Research Article

\title{
Improved Fastener-Based Modelling Method for Reinforced Cold-Formed Steel Shear Walls
}

\author{
Xingxing Wang, Youcheng Li, Wei Wang $(\mathbb{D}$, and Shangxin Gao \\ School of Architecture and Civil Engineering, Jiangsu University of Science and Technology, Zhenjiang, China \\ Correspondence should be addressed to Wei Wang; wangweidimias@sina.com
}

Received 28 July 2019; Accepted 15 October 2019; Published 12 November 2019

Academic Editor: Dimitris Rizos

Copyright (c) 2019 Xingxing Wang et al. This is an open access article distributed under the Creative Commons Attribution License, which permits unrestricted use, distribution, and reproduction in any medium, provided the original work is properly cited.

\begin{abstract}
The fastener-based computational model is improved and extended to predict the shear performance of reinforced cold-formed steel (RCFS) shear walls. The failure mechanism of sheathing-to-stud connections with double-layer wallboards is first analysed, and a method for determining those connections' shear properties is proposed. Numerical models of RCFS shear walls are then established and analysed. Based on simulated results that have been fully validated by previous test results, an equivalent method for perforated RCFS shear walls is proposed. Finally, the application of the improved fastener-based modelling method to mid-rise RCFS shear walls is verified. The following results were obtained. (1) The simulated load-displacement curves can fully reflect shear wall hysteretic characteristics; moreover, the relative errors between the simulated and test results are within 14.2\%. (2) The equivalent method that simplifies the wall segment over an opening as a linear elastic beam is applicable in the case of $1.5<b / d$ (i.e., the ratio of the opening width to the depth of the wall segment over the opening) $\leq 5.0$. (3) The improved fastener-based modelling method can be used to effectively predict the lateral performance of mid-rise RCFS shear walls.
\end{abstract}

\section{Introduction}

Cold-formed steel (CFS) shear walls are the prime lateral load-resisting members of CFS structures. Owing to complex configurations, including CFS steel members, sheathing wallboards, and screw connections, the shear performance of CFS shear walls was mainly investigated through full-scale cyclic loading tests [1-6]. The test results indicated that a failure of the fastener connections between the CFS framing members and the sheathings is the main reason that CFS shear walls fail in terms of shear [7-10], and this type of failure is especially common near the edges of the walls and at the seams, and the failure of fastener connections is often expressed as a bearing failure of the wallboards [11-13]. However, full-scale cyclic loading tests are disadvantageous owing to their high cost, long experimental period, and limited specimens with various test targets. Moreover, the experimental results obtained by various researchers are usually not based on specimens with the exact same configuration. Therefore, it is difficult to form quantitative assessment indexes based on these results, thus narrowing their application. Consequently, an effective numerical simulation method is a crucial and indispensable method for systematically studying the shear performance of CFS shear walls of various configurations.

Sheathing-to-stud connections do not only improve the shear (lateral) capacity of CFS shear walls but also they represent the bracing system of the walls. The slipping deformation of the connections is also the main reason for the nonlinear deformation of the walls. Xuhong et al. [14] and Niari et al. [15] used ANSYS and ABAQUS, respectively, to simulate the shear behaviour of CFS shear walls and found that the simulated load-displacement skeleton curves of the walls agreed well with the test results. Nevertheless, the numerical models could not describe the slipping deformation of sheathing-to-stud connections, making it difficult to obtain the hysteretic characteristics of the walls. Therefore, Peterman et al. [16] characterised the hysteretic behaviour of sheathing-to-stud connections using the Pinching 4 model developed using OpenSees structural 
analysis software. Buonopane et al. [17] further proposed a fastener-based modelling method based on the assumption that the main deformation of the walls is concentrated at the sheathing-to-stud connections regardless of the shear deformation of the wallboards and contacts between the wallboards' edges. The results thus obtained indicated that the fastener-based modelling method can be used to effectively simulate the hysteretic characteristics of CFS shear walls such as strength degradation, stiffness degradation, and pinching.

In order to improve the shear strength, vertical bearing capacity, antioverturning ability, and fire-resistant performance of the walls in mid-rise dwellings with $4 \sim 6$ stories, a reinforced cold-formed steel (RCFS) shear wall that is sheathed with double-layer wallboards on both sides and makes use of continuous concrete-filled rectangular steel tube (CFRST) columns as end studs was proposed by Wang and Le [18] (see Figure 1). However, the fastener-based modelling method is usually used for conventional CFS shear walls, and its applicability to RCFS shear walls should be further investigated. In addition, several researchers focused on the effect of an opening on the shear performance of CFS shear walls [18-21]. Consequently, it is necessary to propose a modelling method specific to the RCFS shear walls, which can both reflect the hysteretic characteristics of the walls and take the effect of the opening into consideration in order to determine the shear performance of the walls for various configurations, thus meeting a computational requirement that would bridge the gap between detailed finite element models and equivalent bracing models [22].

In this study, the fastener-based computational model is improved for predicting the shear performance of RCFS shear walls using OpenSees structural analysis software. The failure mechanism of sheathing-to-stud connections with double-layer wallboards in shear is first analysed, based on which a method for determining the shear properties of those connections is proposed. Improved fastener-based models for RCFS shear walls are then established and validated using previous test results; an equivalent method for perforated RCFS shear walls is proposed further. Finally, the suitability of the application of the improved fastener-based modelling method to mid-rise RCFS shear walls is verified.

\section{Configuration and Shear Behaviour of RCFS Shear Walls}

A typical RCFS shear wall is framed with continuous concrete-filled rectangular steel tube (CFRST) columns, lipped channel section interior studs (i.e., C-section studs), and unlipped channel section tracks and sheathed with gypsum wallboards (GWBs) as a base-layer wallboard combined with Bolivian magnesium boards (BMBs) as a face-layer wallboard using $4.8 \mathrm{~mm}$ diameter self-drilling screws, as depicted in Figure 1(a). Specifically, a CFRST column is welded using two CFS C-section studs face-to-face along the vertical direction to create a tube and filled with fine aggregate concrete. The bottom track is connected to the CFRST column using hold down, whereas the top track is connected to the CFRST column using a reinforced connection, in which a gusset plate and adapting pieces are used to integrate the tracks of adjacent layers, the I-shaped joist, and the CFRST column as a unit by connecting bolts, as shown in Figure 1(b) [23]. The base-layer wallboard is first fixed by screws with larger spacing, and then, the face-layer wallboard is fixed with fasteners' spacing being $150 \mathrm{~mm}$.

Previous test results [18] indicated that the load-displacement curve of the RCFS shear wall subjected to a reversed cyclic load exhibits obvious nonlinear characteristics. This is because the wall comprises various types of materials that exhibit material nonlinearity, and the complex boundary constraints of the wall and abundance of fasteners result in geometric nonlinearity. Consequently, the key points in the numerical simulation of the shear performance of RCFS shear walls include reasonable element types, an accurate definition of the shear properties for sheathing-tostud connections with double-layer wallboards, and effective boundary constraints of both CFRST columns and openings.

\section{Computational Model of RCFS Shear Walls}

3.1. Modelling Method. The computational models of typical RCFS shear walls are shown in Figure 2. The details are as follows:

(1) Reference to the modelling method in [17]; steel frames are subdivided by nodes at fastener locations and are modelled using displacement-based beam elements with appropriate cross-sectional properties. The experimental results in the previous study showed that when the wall damaged, the steel tube and the internal concrete remained as a whole [18]. Therefore, the CFRST column is defined as a composite section without axial deformation, and the cross-sectional properties are determined according to the principle of equivalent flexural rigidity.

(2) As shown in Figure 2(a), without taking into account the joints, the staggered double-layer sheathings on each side of the wall are modelled as a rigid body (i.e., RigidDiaphragm in OpenSees) with slave nodes at each fastener location, and a master node in the centre, and the double rows of fasteners at each joint are simplified as a single row of screw connections because the double rows of fasteners can effectively restrain the out-plane deformation of sheathing wallboards without any change in the shear capacity of the wall $[18,24]$. The rigid body has translation and rotation degrees of freedom only.

(3) For a perforated RCFS shear wall with an opening in the centre, the experimental results in the previous study indicated that the wall segment over the opening plays the role of a coupling beam during the test [18]; therefore, an equivalent method that inspired by Buonopane et al. [17] is proposed, in which the wall segment over the opening is modelled using a series of linear elastic beam-column elements that are connected to the chord studs using ZeroLength element 3, which transfer only vertical forces, as 


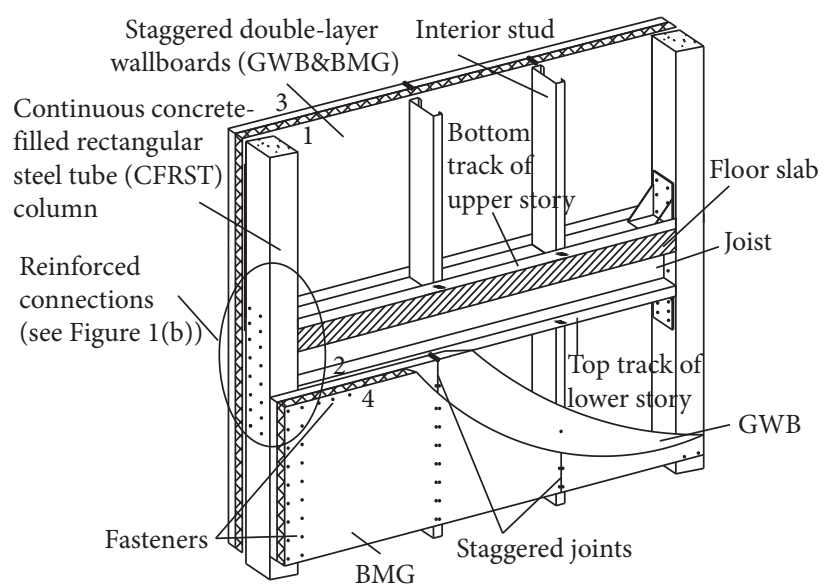

(a)

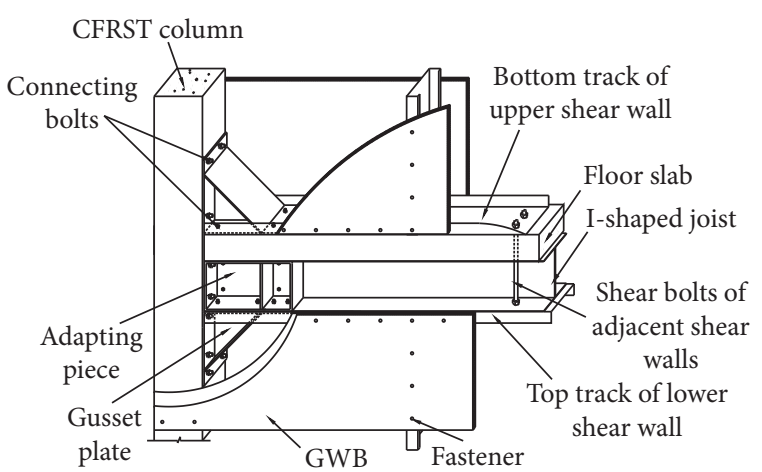

(b)

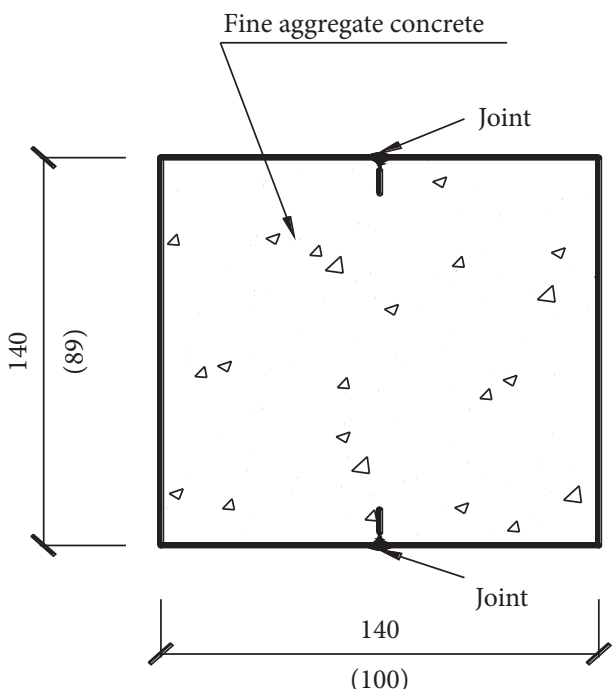

(c)

FIGURE 1: A reinforced cold-formed steel (RCFS) shear wall. (a) Shear wall configurations. (b) Reinforced connection between the CFRST column and top track. (c) Section diagram of the CFRST column.

depicted in Figures 2(b) and 2(c) [17]. The bending moment is transferred from the wall segment to the chord studs through a moment couple of the horizontal forces at the beam ends, i.e., the ZeroLength elements 1 and 2 in Figure 2(c).

(4) ZeroLength elements are used to simulate both track-to-stud and sheathing-to-stud connections. In the case of CFRST column-to-track connections, the reinforced connection on the top was simulated by rotational spring, whose nonlinear behaviour was obtained from previous experimental results by the authors [25]; the CFRST column-to-track connection at the bottom was assumed as fixed constraint. In the case of track-to-internal stud connections, the rotation degrees of freedom of their corresponding ZeroLength elements are released. For sheathing-tostud connections with double-layer wallboards, the determination of the parameters of their corresponding ZeroLength elements is elaborated in Section 3.2.
(5) The out-plane translation degree of freedom of the nodes on the top track is constrained, and the translation degree of freedom of those nodes is coupled along the loading direction in order to simulate the loading beam. The translation degrees of freedom of the nodes on the bottom track are constrained to simulate the connections between the wall and foundation, and the translation degrees of freedom of the nodes at both ends of the interior studs are coupled to the corresponding nodes on the tracks to simulate track-to-stud connections. Previous test results showed that $[18,24]$ compared with shear walls with coupled C-section end studs, no obvious deformation was observed in the steel frames and the track-to-foundation connections of RCFS shear walls because the reinforced end studs restrained the lateral deformation of the walls effectively; besides, the hold downs were wielded by steel plates with a thickness of $4 \mathrm{~mm}$, both strength and stiffness of which were large enough to guarantee the CFRST column-to-track 


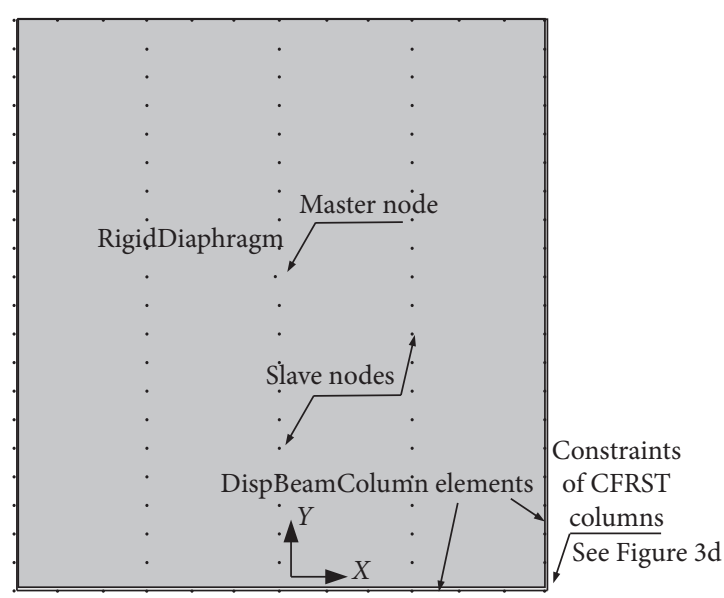

(a)

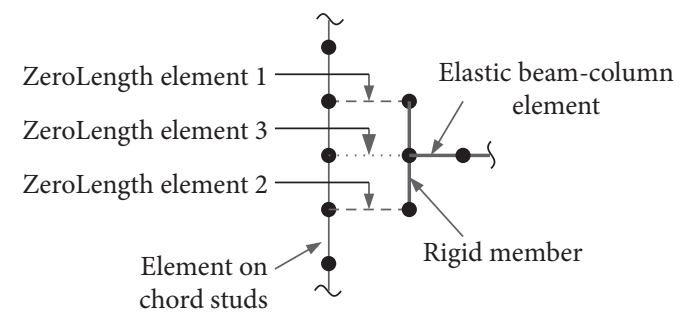

(c)

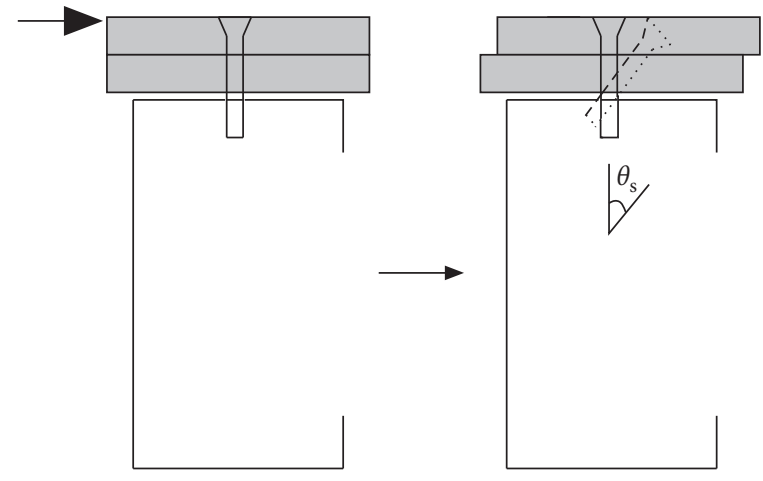

(e)

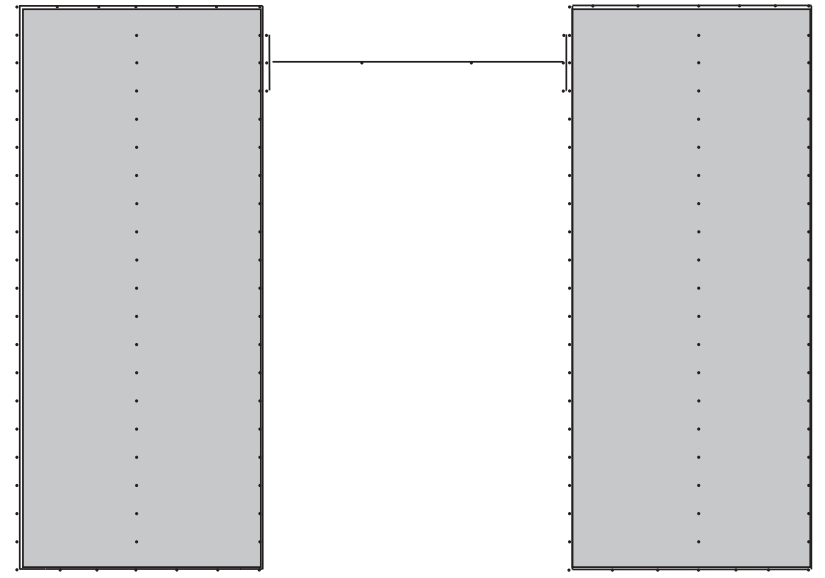

(b)

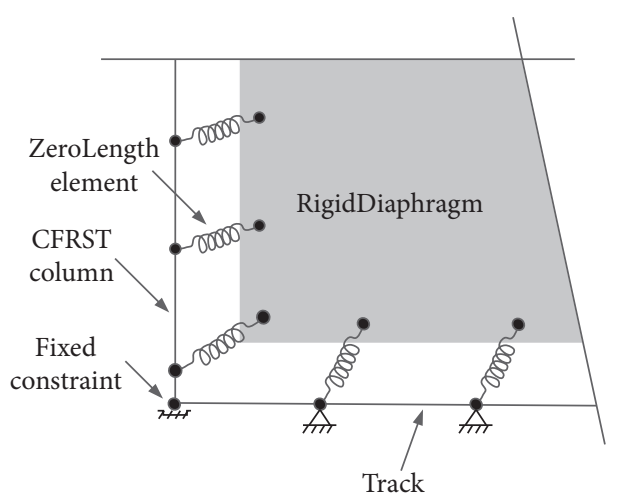

(d)

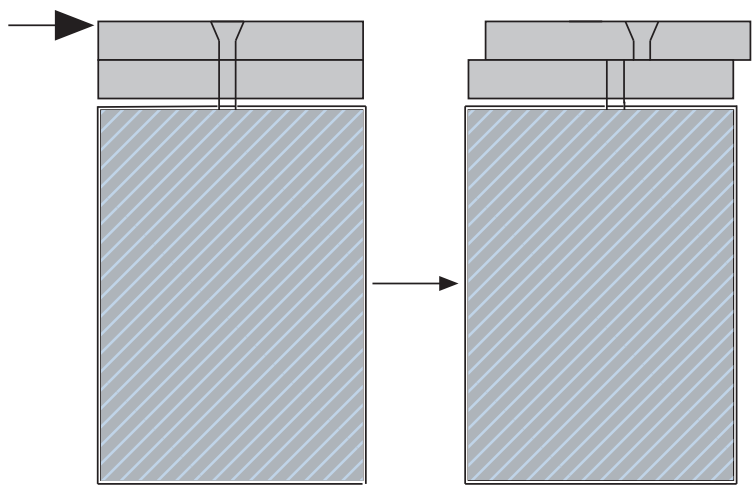

(f)

FIGURE 2: Numerical models of RCFS shear walls. (a) Equivalent of double-layer sheathings. (b) Equivalent method of an opening. (c) Boundary treatments of an opening [17]. (d) Boundary constraints. (e) Failure mode 1 of sheathing-to-stud connections with doublelayer wallboards. (f) Failure mode 2 of sheathing-to-stud connections with double-layer wallboards.

connections. Therefore, the track-to-foundation connections are assumed as pin-connections, while the fixed connections between the CFRST columns and the bottom track are adopted to approximately simulate the effect of hold downs (see Figure 2(d)). For rigid bodies on both sides of the wall, their rotation degrees of freedom around the $X$ and $Y$ directions and outplane translation degree of freedom are constrained to ensure that the sheathings of the wall exhibit only inplane translation and rotation.
3.2. Parameter Determination of Sheathing-to-Stud Connections with Double-Layer Wallboards. As the sheathings on both sides of the wall are assumed to be rigid bodies, only inplane (i.e., along the $X$ and $Y$ directions in Figure 2(a)) loaddeformation relationships of the fasteners in shear are considered.

Cyclic loading tests of the RCFS shear walls show that the fasteners' failure modes can be summarised as screw tilting and being pulled out (hereinafter referred to as failure mode 1) and a screw being sheared off (hereinafter referred to as failure 
mode 2), as shown in Figures 2(e) 2(f). Fasteners on the tracks and interior studs mainly exhibited failure mode 1. The moment screw heads were then completely sunk into the face-layer wallboard, and the largest compression area of the sheathings was formed (see dotted line in Figure 2(e)), and the wall reached its shear capacity. When the load continued to increase, the screws were pulled through the face-layer and base-layer wallboards successively, thus resulting in the failure of the wall. Failure mode 2 was mainly observed in the fasteners in the CFRST columns, especially in the case of those fasteners in the $140 \mathrm{~mm}$ deep CFRST columns of greater stiffness. Owing to the restriction imposed by the concrete core on the screw tilting, no obvious extrusion deformation of the sheathings was observed when the fasteners were in shear.

The Pinching 4 model is used to define the hysteretic properties of sheathing-to-stud connections with doublelayer wallboards based on the test results listed in Table 1 [27]. As shown in Figure 3, the Pinching 4 model makes use of 16 parameters (i.e., eight strength parameters relative to points $1 \sim 8$ and eight corresponding deformation parameters) to define the skeleton curve and six parameters to define the unloading-reloading paths. Damage factors and their corresponding limit indexes are used to determine the hysteretic damage criterion of the loading and unloading stiffness and strength [28]. The specific values of those parameters are described in the following subsections.

\subsubsection{Parameters of Skeleton Curve}

\section{A. Failure Mode 1}

(1) As shown in Figure 1(a), each stud has double rows of screw connections. Previous experimental results $[18,23]$ showed that the group effect of sufficient screws ensured the double-layer wallboards working as a rigid body; before the wall reached its shear capacity, the relative movements of the base-layer and face-layer wallboards allowed the screws to compress the wallboard of screw holes entirely. Therefore, the fasteners' shear strength in each stage are assumed to be evaluated as the sum of the corresponding shear strength of each single-layer sheathing-to-stud connection, which is represented as

$$
\begin{gathered}
f_{e e q-\mathrm{I}}=f_{e 1}+f_{e 2}, \\
f_{y e q-\mathrm{I}}=f_{y 1}+f_{y 2}, \\
f_{m e q-\mathrm{I}}=f_{m 1}+f_{m 2},
\end{gathered}
$$

where $f_{\text {eeq-I }}, f_{\text {yeq-I }}$, and $f_{\text {meq-I }}$ are the equivalent shear strength of a fastener with failure mode 1 in the elastic stage (i.e., points 1 and 5 in Figure 3), yield stage (i.e., points 2 and 6 in Figure 3), and peak stage (i.e., points 3 and 7 in Figure 3 ), respectively; and $f_{e 1}, f_{y 1}$, and $f_{m 1}$ and $f_{e 2}, f_{y 2}$, and $f_{m 2}$ are the shear strengths of the single-layer sheathing-to-stud connections relative to the base-layer and face-layer wallboards in the elastic stage, yield stage, and peak stage, respectively.

(2) During the postload period, screws were pulled through the face-layer and base-layer wallboards successively, the wall entered into the damage stage either because of loose screws in the base-layer wallboards, or screws pulled through face-layer wallboards, thus almost only single-layer wallboards provided the constraints to steel frames. In this case, the equivalent shear strength of a fastener $f_{\text {ueq-I }}$ (i.e., points 4 and 8 in Figure 3) can be determined to be the larger shear strength of the single-layer sheathing-to-stud connections corresponding to the baselayer $\left(f_{u 1}\right)$ and face-layer $\left(f_{u 2}\right)$ wallboards when the connections reach their failure deformation, which can be expressed as

$$
f_{\text {ueq-I }}=\max \left(f_{u 1}, f_{u 2}\right)
$$

(3) Owing to the extrusion deformation of the sheathings and the relative sliding between the base-layer and face-layer wallboards caused by loose screws, the deformation of the previous stage should be reckoned in that corresponding to the subsequent stage, see equations (5)-(8). Furthermore, when a fastener reaches its peak shear strength, the deformation should be converted using equation (7) owing to the screw tilting.

$$
\begin{aligned}
& d_{e e q-\mathrm{I}}=d_{e 1}+d_{e 2}, \\
& d_{y e q-\mathrm{I}}=d_{y 1}+d_{y 2}+d_{e e q-\mathrm{I}} \\
& d_{m e q-\mathrm{I}}=\frac{d_{m 1}+d_{m 2}}{\cos \theta_{s}+d_{y e q-\mathrm{I}}} \\
& d_{u e q-\mathrm{I}}=d_{u 1}+d_{u 2}+d_{m e q-\mathrm{I}}
\end{aligned}
$$

where $d_{e e q-\mathrm{I}}, d_{\text {yeq-I }}, d_{\text {meq-I }}$, and $d_{\text {ueq-I }}$ are the equivalent shear deformations of a fastener that exhibits failure mode 1 in the elastic stage (i.e., points 1 and 5 in Figure 3), yield stage (i.e., points 2 and 6 in Figure 3), peak stage (i.e., points 3 and 7 in Figure 3), and damage stage (i.e., points 4 and 8 in Figure 3), respectively; $d_{e 1}, d_{y 1}, d_{m 1}$, and $d_{u 1}$ and $d_{e 2}, d_{y 2}, d_{m 2}$, and $d_{u 2}$ are the shear deformations of the single-layer sheathing-to-stud connections relative to the baselayer and face-layer wallboards in the elastic stage, yield stage, peak stage, and damage stage, respectively; and $\theta_{\mathrm{s}}$ is the angle between a screw and its initial position when the screw head is completely sunk into the face-layer wallboard, which can be determined according to the screw's specification and sheathing thickness.

\section{B. Failure Mode 2}

In the case of a fastener that exhibits failure mode 2, its shear capacity is relatively larger than that of a 
TABLE 1: Single-layer sheathing-to-stud connection properties [26].

\begin{tabular}{|c|c|c|c|c|c|c|c|c|c|c|c|c|c|}
\hline Projects & $f_{\mathrm{e}}(\mathrm{N})$ & $d_{\mathrm{e}}(\mathrm{mm})$ & $f_{\mathrm{y}}(\mathrm{N})$ & $d_{\mathrm{y}}(\mathrm{mm})$ & $f_{\mathrm{p}}(\mathrm{N})$ & $d_{\mathrm{p}}(\mathrm{mm})$ & $f_{\mathrm{u}}(\mathrm{N})$ & $d_{\mathrm{u}}(\mathrm{mm})$ & $E_{\mathrm{t}}(\mathrm{J})$ & $E_{\mathrm{f}}(\mathrm{J})$ & $r_{\text {Disp }} \mathrm{P}$ & $r_{\text {Force }} \mathrm{P}$ & $u_{\text {Force }} \mathrm{P}$ \\
\hline GWB-15 & 205 & 0.37 & 430 & 1.17 & 515 & 2.14 & 440 & 2.50 & 6.1 & 5.3 & & & \\
\hline GWB-20 & 275 & 0.55 & 565 & 1.89 & 680 & 3.34 & 575 & 4.20 & 12.3 & 10.9 & 0.5 & 0.3 & 0.4 \\
\hline GWB-25 & 260 & 0.54 & 540 & 2.18 & 660 & 3.18 & 560 & 4.17 & 18.6 & 16.1 & & & \\
\hline BMG-15 & 305 & 0.41 & 620 & 1.29 & 760 & 2.06 & 645 & 2.85 & 14.1 & 12.8 & & & \\
\hline BMG-20 & 295 & 0.55 & 615 & 1.70 & 745 & 2.99 & 635 & 4.78 & 19.7 & 17.6 & 0.5 & 0.3 & 0.1 \\
\hline BMG-25 & 300 & 0.50 & 630 & 2.11 & 750 & 3.82 & 640 & 4.55 & 28.8 & 24.7 & & & \\
\hline CSB-20 & 580 & 1.17 & - & - & 1455 & 3.65 & - & - & - & - & - & - & - \\
\hline CSB-25 & 720 & 1.76 & - & - & 1790 & 5.08 & - & - & - & - & - & - & - \\
\hline
\end{tabular}

GWB, BMG, and CSB represent $12 \mathrm{~mm}$ gypsum wallboard, $12 \mathrm{~mm}$ bolivian magnesium board, and $12 \mathrm{~mm}$ calcium silicate board, respectively; 15,20 , and 25 are the edge distances often being used in the fields of interior stud, track, and end stud, respectively; $f_{\mathrm{e}}, d_{\mathrm{e}}, f_{\mathrm{y}}, d_{\mathrm{y}}, f_{\mathrm{p}}, d_{\mathrm{p}}, f_{\mathrm{u}}$, and $d_{\mathrm{u}}$ are the elastic strength, yield strength, peak strength, failure strength, and their relative displacements, respectively; $E_{\mathrm{t}}$ and $E_{\mathrm{f}}$ are the test and calculated results of the hysteretic curve's cumulative energy, respectively; the meanings of $r_{\text {Disp }} \mathrm{P}, r_{\text {Force }} \mathrm{P}$, and $u_{\text {Force }} \mathrm{P}$ are identical to those in Figure 3 .

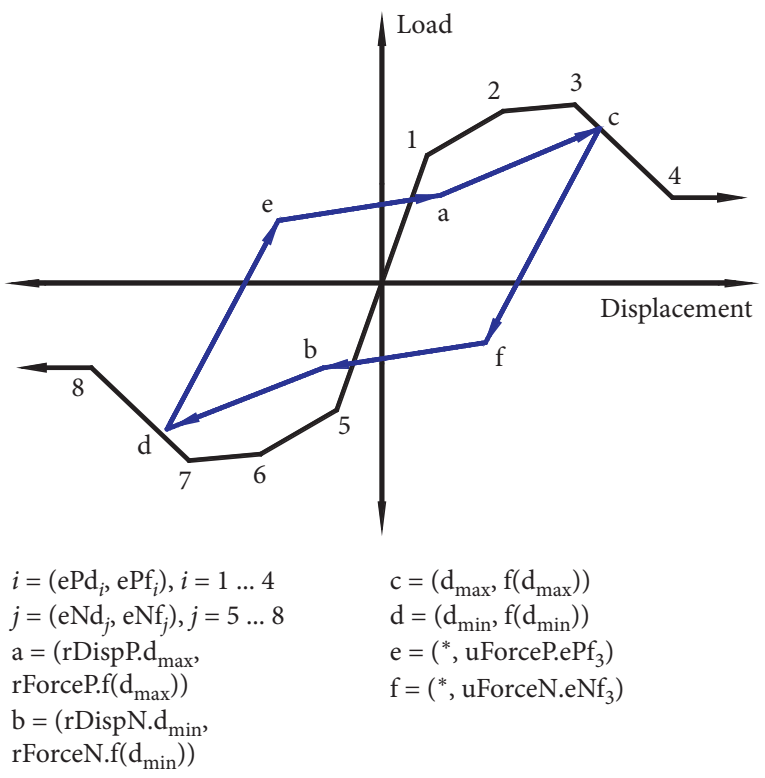

FIGURE 3: Pinching 4 model [17].

fastener that exhibits failure mode 1 , and its shear strength is thus approximately determined based on the test results of calcium silicate board-to-stud connections (their failure mode is that of a screw being sheared off) in Table 1. As calcium silicate board-to-stud connections mainly exhibit brittle failure and their load-deformation curves have no obvious yield limit, the shear strength of a fastener that exhibits failure mode 2 in each stage can be determined by equations (9)-(12) given as follows:

$$
\begin{aligned}
& f_{\text {eeq-II }}=f_{m} \frac{f_{\text {eeq }-\mathrm{I}}}{f_{\text {meq-I }}}, \\
& f_{\text {yeq-II }}=f_{m} \frac{f_{\text {yeq }-\mathrm{I}}}{f_{\text {meq-I }}}, \\
& f_{\text {meq-II }}=f_{m}, \\
& f_{\text {ueq-II }}=f_{m} \frac{f_{\text {ueq-I }}}{f_{\text {meq-I }}},
\end{aligned}
$$

where $f_{\text {eeq-II }}, f_{\text {yeq-II }}, f_{\text {meq-II }}$, and $f_{\text {ueq-II }}$ are the equivalent shear strength of a fastener that exhibits failure mode 2 in the elastic stage (i.e., points 1 and 5 in Figure 3), yield stage (i.e., points 2 and 6 in Figure 3), peak stage (i.e., points 3 and 7 in Figure 3), and damage stage (i.e., points 4 and 8 in Figure 3), respectively; $f_{m}$ is the peak shear strength of the calcium silicate board-to-stud connection; and $f_{\text {eeq- }-\mathrm{I}}$, $f_{\text {yeq-I}}, f_{\text {meq-I}}$, and $f_{\text {ueq-I }}$ are identical to those in equations (1)-(4).

The shear deformation of a fastener in each stage can be determined using equations (13)-(16). In order to consider the restraint of the concrete core on screw tilting, $d_{e e q-\mathrm{II}}, d_{\text {yeq-II }}$, and $d_{\text {meq-II }}$ are not reckoned in $d_{\text {yeq-II }}, d_{\text {meq-II }}$, and $d_{\text {ueq-I }}$, respectively.

$$
\begin{aligned}
& d_{e e q-\mathrm{II}}=d_{e 1}+d_{e 2}, \\
& d_{y e q-\mathrm{II}}=d_{y 1}+d_{y 2}, \\
& d_{m e q-\mathrm{II}}=\frac{d_{m 1}+d_{m 2}}{\cos \theta_{s}} \\
& d_{u e q-\mathrm{II}}=d_{u 1}+d_{u 2},
\end{aligned}
$$

where $d_{\text {eeq-II }}, d_{y e q-\mathrm{II}}, d_{m e q-\mathrm{II}}$, and $d_{\text {ueq-II }}$ are the equivalent shear deformations of a fastener that exhibits failure mode 2 in the elastic stage (i.e., points 1 and 5 in Figure 3), yield stage (i.e., points 2 and 6 in Figure 3), peak stage (i.e., points 3 and 7 in Figure 3), and damage stage (i.e., points 4 and 8 in Figure 3), respectively; and $d_{e 1}, d_{e 2}, d_{y 1}, d_{y 2}, d_{m 1}$, $d_{m 2}, d_{u 1}$, and $d_{u 2}$ are identical to those in equations (5)-(8)

3.2.2. Hysteretic Parameters. According to the hysteretic characteristics of the sheathing-to-stud connections in shear, the cycle hysteretic damage is adopted to fit their load-deformation curves, and their hysteretic parameters can be determined by the trial method based on a criterion that the relative error of the fitted cumulative energy dissipation and the test result are no more than $15 \%$. 
As depicted in Figure 3, the hysteretic parameters relative to points $a, b, e$, and $f$ play a dominant role in the pinching characteristics, thus affecting the energy dissipation capacity of the sheathing-to-stud connection. Owing to the group effect of sufficient screws and effective constraints of reinforced end studs, the degradation of cycles with the same amplitude is not as significant as shear walls with coupled C-section end studs; moreover, as listed in Table 1, the hysteretic curve's cumulative energy of single-layer sheathing-to-stud connections of the GWB is significantly lower than that of the BMG, especially for those connections with little end stage (i.e., GWB-15). Hence, in order to ensure the reliability of the calculated shear performance of RCFS shear walls, the hysteretic parameters of single-layer sheathing-to-stud connections corresponding to the BMG with smaller values relative to points $\mathrm{a}, \mathrm{b}, \mathrm{e}$, and $\mathrm{f}$ are taken as the hysteretic properties of the sheathing-to-stud connection with double-layer wallboards.

\section{Model Verification and Discussion}

4.1. Model Description. In order to verify the improved fastener-based modelling method, comparative analyses between the simulated results and the test results of typical RCFS shear walls carried out by Wang and Ye [18] are conducted. The details of each wall configuration are provided in Table 2 and Figure 4.

According to the tested material properties [26], the elastic modulus, Poisson's ratio, and yield strength of the CFS members are $2.06 \times 10^{5} \mathrm{MPa}, 0.3$, and $395 \mathrm{MPa}$, respectively. As there were few fasteners on the $89 \mathrm{~mm}$ deep concrete-filled rectangular steel tube (CFRST) columns (specimen RW1) that exhibited failure mode 2 while all the screws on the $140 \mathrm{~mm}$ deep CFRST columns (specimens RW2 and RW3) were sheared off during the test, the shear properties of those fasteners on the reinforced end studs of specimen RW1 and specimens RW2 and RW 3 are defined as failure mode 1 and failure mode 2, respectively, in Section 3.2.1. Furthermore, the contribution of an autoclaved lightweight concrete slab to a fastener's shear strength is neglected as it has a lower strength, and the effects of the input parameters of the corresponding fasteners on the interior studs and tracks of specimens RW2 and RW3 are evaluated as the properties of the single-layer BMG-to-stud connections. According to the test results [27] and based on an assumption of the load-deformation curves being symmetrical in forward and reverse loading, only eight parameters are required to be defined for forward loading (see Table 3 for details). In this case, because the hysteretic parameters relative to points $a, b, e$, and $f$ of the BMG-tostud connection are lower than those of the GWB-to-stud connection, the values of the former are considered to be the hysteretic properties of the sheathing-to-stud connection with double-layer wallboards.

4.2. Comparisons between Simulated and Test Results. After establishing the numerical model for each specimen, inputting the material properties of the steel frame and fasteners, and applying the boundary constraints, multistage cyclic displacements are applied to the coupled node of the top track until each model's displacement reaches a value at which damage occurs. It is noted that the tests were conducted in both the single-cycle force-control mode and three-cycle displacement-control mode, and the former was replaced with the latter when the specimen yielded; during the numerical analysis, the force-control mode was approximately converted into several displacement levels with a displacement step of $5 \mathrm{~mm}$; the displacement step of the three-cycle displacement-control mode is $10 \mathrm{~mm}$, which is the same as that used in the tests [18].

The load-displacement curve comparisons of the simulated and test results of the specimens are shown in Figures 5(a) 5(c). It should be noted that as explained in Section 3.2.2, owing to the effective constraints of reinforced end studs, the degradation of cycles with the same amplitude is not as significant as shear walls with coupled C-section end studs; thus, only the first hysteretic loop of each load level was considered in the comparison. It can be observed that the simulated curves agree well with the test results and reflect the hysteretic characteristics of the walls. It should be noted that the fullness of the dashed loops in Figure 5(a) is less than that of the test result; this is because the stiffness of the $89 \mathrm{~mm}$ deep CFRST columns is lower and the deformation of the steel frame during the postload period is obvious. However, for the numerical model, it is difficult to reflect the large deformation such as distortion of the steel frame, thus resulting in a conservative calculated energy dissipation capacity of the wall. The steel frame deformation of the wall with $140 \mathrm{~mm}$ deep CFRST columns is relatively small, and the energy dissipation due to the steel frame deformation is not obvious; thus, the fullness of the dashed loops is very close to that of the test result (see Figures 5(b) and $5(\mathrm{c})$ ).

Table 4 lists the comparisons of the simulated and test results [18] for each specimen. It can be concluded that good agreements can be observed between the test and simulated results with the relative errors within $14.2 \%$, thus indicating the correctness and reliability of the numerical models established in this study.

\subsection{Discussion on the Application of the Equivalent Method} to Perforated RCFS Shear Walls. The cyclic loading test results [18] show that the empirical equations stated in AISI S213 are not applicable for calculating the shear capacity of perforated RCFS shear walls, and the method of simplifying the wall segments over and on both sides of an opening as a coupling beam and composite columns, respectively, can be used to accurately predict the shear capacity of a wall with an opening in the centre. The shear capacity of a wall with an opening in the side (i.e., the wall with a door in the side) can be evaluated as the shear strength corresponding to the net sheathed wall length.

Consequently, in order to clearly define the application scope of the equivalent method to perforated RCFS shear walls-in particular, perforated RCFS shear walls with an opening in the centre-sixteen numerical models with 
TABLE 2: Details of test specimens $[18,23]$.

\begin{tabular}{|c|c|c|c|c|c|c|c|}
\hline \multirow{3}{*}{$\begin{array}{l}\text { Specimen } \\
\text { number }\end{array}$} & \multicolumn{2}{|c|}{ Section type of CFS studs } & \multirow{3}{*}{$\begin{array}{l}\text { Opening size } \\
(b \times h / d) / \mathrm{m}\end{array}$} & \multirow{3}{*}{$\begin{array}{l}\text { Loading regime } \\
\left(\Delta_{\mathrm{el}} / \Delta_{\mathrm{f}}\right) \mathrm{mm}\end{array}$} & \multicolumn{3}{|c|}{ Sheathing setups ${ }^{\mathrm{a}}$} \\
\hline & \multirow[t]{2}{*}{ Interior studs } & \multirow[t]{2}{*}{ CFRST columns } & & & $\begin{array}{l}\text { Base } \\
\text { layer }\end{array}$ & \multicolumn{2}{|c|}{ Face layer } \\
\hline & & & & & 1 & 3 & 4 \\
\hline RW1 & C89 & $\square 89 \times 100 \times 0.9$ & \multirow[t]{2}{*}{-} & $15 / 55$ & \multirow{2}{*}{$\begin{array}{l}\text { BMG } \\
\text { BMG }\end{array}$} & \multicolumn{2}{|c|}{ GWB } \\
\hline RW2 & $\mathrm{C} 140$ & $\square 140 \times 140 \times 1.5$ & & $15 / 65$ & & GWB & $\mathrm{ALC}^{1}$ \\
\hline RW3 & C140 & $\square 140 \times 140 \times 1.5$ & $\begin{array}{c}1.5 \mathrm{~m} \times 2.4 \mathrm{~m} / \\
0.6 \mathrm{~m}\end{array}$ & $15 / 75$ & BMG & GWB & $\mathrm{ALC}^{1}$ \\
\hline MRW1 & C89 & $\square 89 \times 100 \times 0.9$ & \multirow{2}{*}{ - } & $20 / 70$ & BMG & \multicolumn{2}{|c|}{ GWB } \\
\hline MRW2 & $\mathrm{C} 140$ & $\square 140 \times 140 \times 1.5$ & & $20 / 80$ & BMG & GWB & - \\
\hline MRW3 & $\mathrm{C} 140$ & $\square 140 \times 140 \times 1.5$ & $\begin{array}{c}1.5 \mathrm{~m} \times 1.5 \mathrm{~m} / \\
0.6 \mathrm{~m}\end{array}$ & $20 / 90$ & BMG & GWB & - \\
\hline
\end{tabular}

Note: $\square-89$ and $\square-140$ mean $89 \mathrm{~mm}$ deep and $140 \mathrm{~mm}$ deep end studs, respectively. RRW1 RW3 and MRW1 MRW3 are typical single-layer and mid-rise RCFS shear wall specimens, respectively; the width of all specimens is $3.6 \mathrm{~m}$, and the heights of specimens RW1 RW3 and MRW1 MRW3 are $3.0 \mathrm{~m}$ and $6.36 \mathrm{~m}$, respectively; $\mathrm{b}$ and $\mathrm{h}$ are the width and height of an opening, respectively; $\mathrm{d}$ is the height of the wall segment over an opening; $\Delta_{\mathrm{el}}$ and $\Delta_{\mathrm{f}}$ are the approximate elastic limit and the failure displacement of each specimen; the single-cycle mode with a displacement step of $5 \mathrm{~mm}$ is of the three-cycle mode with a displacement step of $10 \mathrm{~mm}$; the steel of all specimens is of grade $345 \mathrm{MPa} ;{ }^{a}$ sheathing setups (see Figure 1 ); ${ }^{1} 50 \mathrm{~mm}$ autoclaved lightweight concrete slab; the fastener spacing of each specimen was $150 \mathrm{~mm}$.

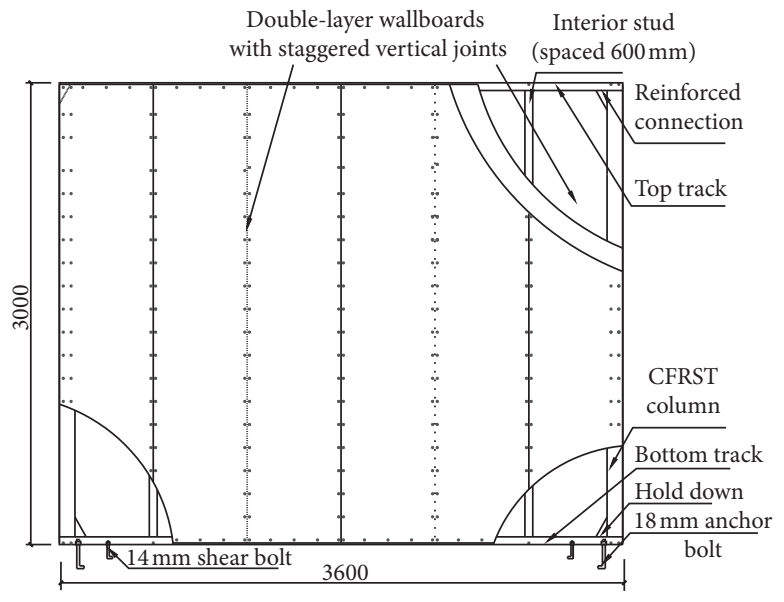

(a)

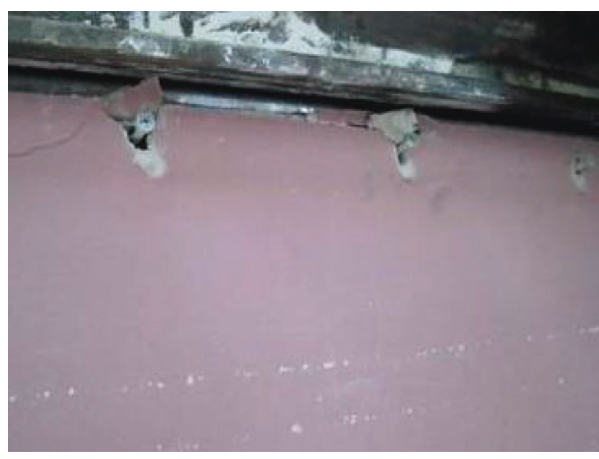

(c)

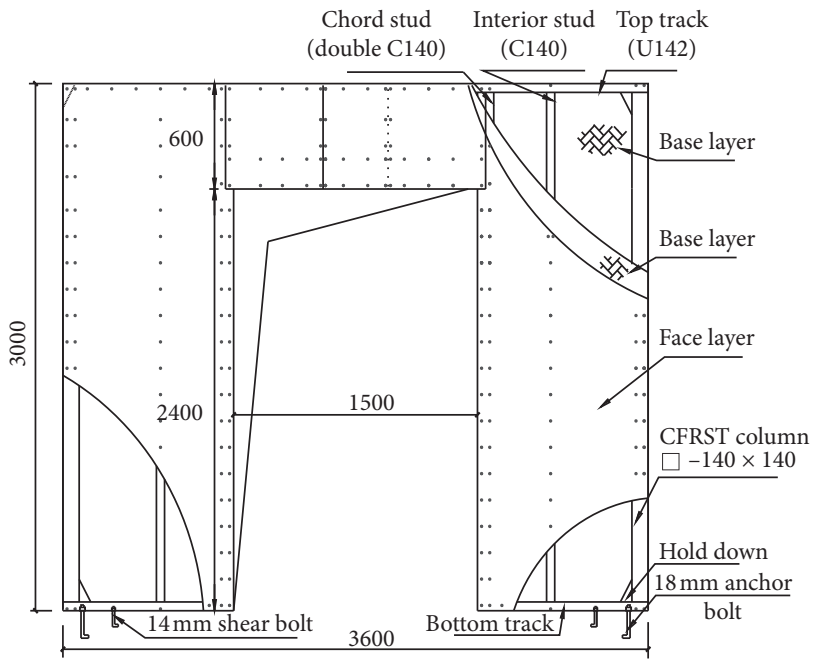

(b)

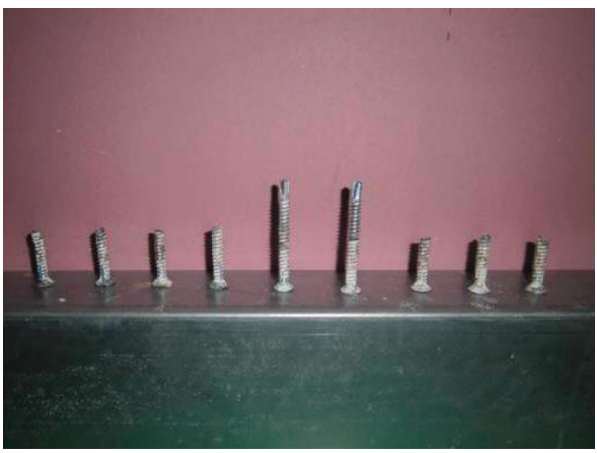

(d)

FIgURE 4: Details of specimens [18]. (a) Typical full-sheathed RCFS shear wall. (b) Typical perforated RCFS shear wall. (c) Failure Mode 1. (d) Failure Mode 2.

various configurations are established, and the simulated and simplified calculated results of those models are compared. Details of each numerical model are listed in Table 5, where IW1-IW8 are internal shear walls with a door, whose studs' section and sheathing setups are the same as those of specimen RW1, and OW1-OW8 are external shear walls with a window, whose studs' section and sheathing setups are the same as those of specimen RW3. 
TABLE 3: Input parameters of fasteners.

\begin{tabular}{|c|c|c|c|c|c|c|c|c|}
\hline \multirow{2}{*}{ Projects } & \multicolumn{5}{|c|}{ GWB and $\mathrm{BMG}$} & \multicolumn{3}{|c|}{ BMG } \\
\hline & Interior studs & Tracks & $\square-89$ & $\square-140$ & Chord studs & Interior studs & Tracks & $\square-140$ \\
\hline$d_{\text {eeq }}(\mathrm{mm})$ & 0.78 & 1.10 & 1.04 & 1.04 & 1.04 & 0.41 & 0.55 & 0.50 \\
\hline$d_{\text {yeq }}(\mathrm{mm})$ & 3.24 & 4.96 & 4.29 & 4.29 & 5.33 & 1.69 & 2.47 & 2.11 \\
\hline$d_{\text {meq }}(\mathrm{mm})$ & 7.75 & 11.76 & 7.53 & 7.53 & 12.86 & 3.75 & 5.45 & 3.82 \\
\hline$d_{\text {ueq }}(\mathrm{mm})$ & 25.0 & 25.0 & 25.0 & 35.0 & 40.0 & 40.0 & 40.0 & 40.0 \\
\hline$f_{\text {eeq }}(\mathrm{N})$ & 509 & 570 & 564 & 847 & 564 & 303 & 299 & 301 \\
\hline$f_{\text {yeq }}(\mathrm{N})$ & 1050 & 1181 & 1171 & 1568 & 1171 & 622 & 616 & 628 \\
\hline$f_{\text {meq }}(\mathrm{N})$ & 1273 & 1411 & 1437 & 1760 & 1411 & 758 & 747 & 758 \\
\hline$f_{\text {ueq }}(\mathrm{N}$ & 50 & 50 & 50 & 50 & 50 & 50 & 50 & 50 \\
\hline$r_{\text {Disp }} \mathrm{P} / r_{\text {Force }} \mathrm{P} / u_{\text {Force }} \mathrm{P}$ & & & & & & $0.5 / 0.3 / 0.1$ & & \\
\hline$\beta_{\mathrm{K} 1,2} / \beta_{\mathrm{K} 3,4} / \beta_{\text {Klimit }}$ & & - & & & & $0.5 / 1.5 / 0.1$ & & \\
\hline$\beta_{\mathrm{D} 1,2} / \beta_{\mathrm{D} 3,4} / \beta_{\text {Dlimit }}$ & & & & & & $0.45 / 1.5 / 0.1$ & & \\
\hline$\beta_{\mathrm{F} 1,2} / \beta_{\mathrm{F} 3,4} / \beta_{\text {Flimit }}$ & & & & & & $0.0 / 0.0 / 0.0$ & & \\
\hline
\end{tabular}

$\square-89$ and $\square-140$ mean $89 \mathrm{~mm}$ deep and $140 \mathrm{~mm}$ deep end studs, respectively; $d_{\text {eeq }}, d_{\text {yeq }}, d_{\text {meq, }}$, and $d_{\text {ueq }}$ are shear deformations and $f_{\text {eeq }}, f_{\text {yeq, }}, f_{\text {meq }}$, and $f_{\text {ueq }}$ are shear strength of sheathing-to-stud connections in each stage; the meanings of $r_{\mathrm{Disp}} \mathrm{P}, r_{\mathrm{Force}} \mathrm{P}$, and $u_{\mathrm{Force}} \mathrm{P}$ are identical to those in Figure $3 ; \beta_{\mathrm{K} 1,2}, \beta_{\mathrm{K} 3,4}, \beta_{\mathrm{K} l i m i t}$ $\beta_{\mathrm{D} 1,2}, \beta_{\mathrm{D} 3,4}, \beta_{\mathrm{Dlimit}}, \beta_{\mathrm{F} 1,2}, \beta_{\mathrm{F} 3,4}$, and $\beta_{\mathrm{Flimit}}$ are the damage factors and their corresponding limit indexes relative to loading and unloading stiffness and strength.

Table 5 and Figure 6 show the simulated and simplified calculated results of each wall. It can be concluded that there is no stable relationship between the shear capacity and opening ratio; with regard to some walls with the same opening ratio, their shear capacities are different. Therefore, the empirical equations for perforated shear walls described in AISI S213 are not suitable for perforated RCFS shear walls, which has also been concluded by Wang and Ye [18]. In the case of walls IW1 and OW1, the relative errors of their shear capacities between the simulated and simplified calculated results are within 5\%. The simulated shear capacities of walls IW2-IW7 and walls OW2-OW7 are mostly lower than the simplified calculated results, and their relative errors are within $9 \%$. The simulated results of walls IW8 and OW8 are higher than their simplified calculated results. Furthermore, the simulated results are close to the shear strength corresponding to the net sheathed wall length (i.e., the values in brackets).

It can be concluded that the application scope of the equivalent method to perforated RCFS shear walls is closely related to the opening size. (1) If $b / d$ (i.e., the ratio of the opening width to the depth of the wall segment over an opening) $\leq 1.5$, the weakening impact of the opening on the shear capacity of a wall can be neglected. (2) If $1.5<b / d \leq 5.0$, the wall segment over an opening can play the role of a coupling beam, and the shear capacity of the wall can be determined by using the equivalent method of simplifying the wall segment as a linear elastic beam. (3) If $b / d>5.0$, the shear capacity of a wall can be approximately evaluated as the shear strength corresponding to the net sheathed wall length because the wall segments over and on both sides of an opening may be insufficient for forming a rigid frame force mechanism.

4.4. Application of Improved Fastener-Based Modelling Method to Mid-Rise RCFS Shear Walls. In order to verify the application of the improved fastener-based modelling method to mid-rise RCFS shear walls, typical mid-rise test specimens [23] are modelled and analysed. Details of each specimen are summarised in Table 2.
According to the configurations of each specimen, the numerical models of mid-rise RCFS shear walls are established. Considering specimen MRW1 as an example, as shown in Figure 7, the modelling process is as follows:

(1) Each floor of the specimen is separately modelled, and the nodes at the joist and adjacent tracks connected to the joist have the same coordinates.

(2) In addition to coupling the translation degrees of freedom of the nodes at both ends of the interior studs to those of the corresponding nodes at the tracks, all the degrees of freedom of the nodes at the joist and adjacent tracks are coupled in order to simulate the connection of the adjacent steel frames.

(3) As the in-plane stiffness of the floor is much larger than the shear stiffness of the shear wall, the joist is assumed to be a rigid beam. Furthermore, all the nodes at the joist are coupled, and one of the nodes is considered as the loading point of the lower wall segment.

(4) All the degrees of freedom of the nodes at the adjacent end studs are coupled in order to simulate the continuous CFRST columns.

The numerical models of the specimens MRW1-MRW3 are established, and after inputting the material properties of the steel frames and fasteners as well as applying the boundary constraints, multistage inverted triangle cyclic displacements are imposed on the coupled node of each floor. The displacement step is considered to be $5 \mathrm{~mm}$, which is the same as that used in the tests [23]. The simulated results of each specimen were compared with the experimental data. According to the failure features of the specimens [23], the behaviour of the upper storey remained essentially elastic when the lower wall segment reached its failure load. Thus, the comparisons of the characteristic parameters of the skeleton curves stated below were focused on the lower wall segments.

Figures 5(d) 5(i) and Table 6 show the comparisons of the simulated and test results of each specimen. Good 


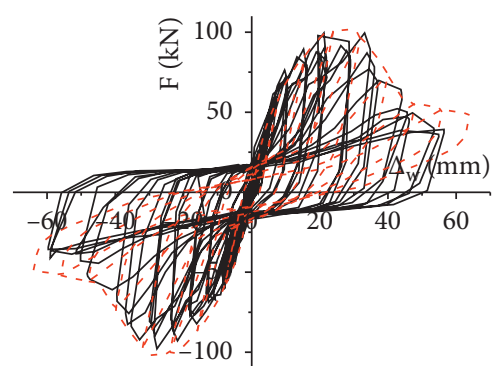

_ Test result [23]

- - - Simulated result

(a)

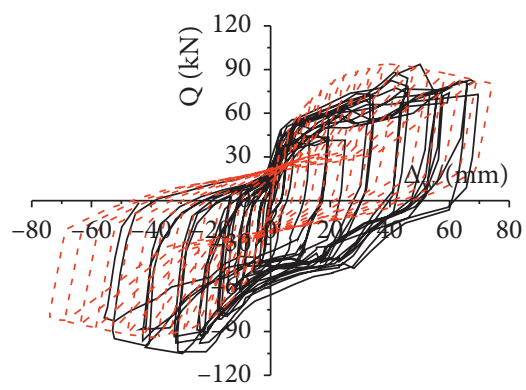

— Test result [23]

- - - Simulated result

(d)

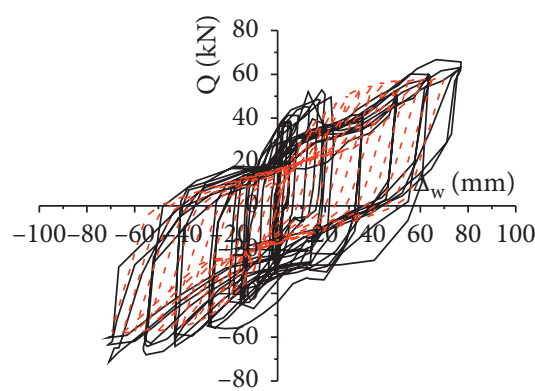

_ Test result [23]

- - Simulated result

(g)

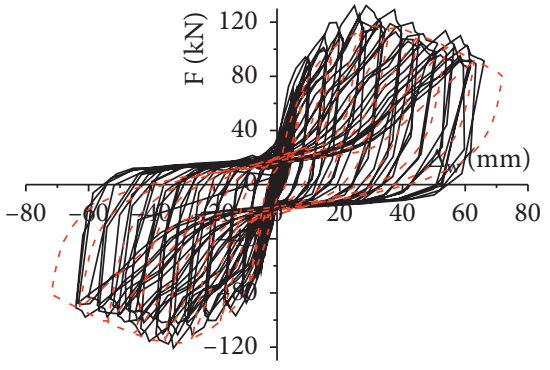

— Test result [23]

- - Simulated result

(b)

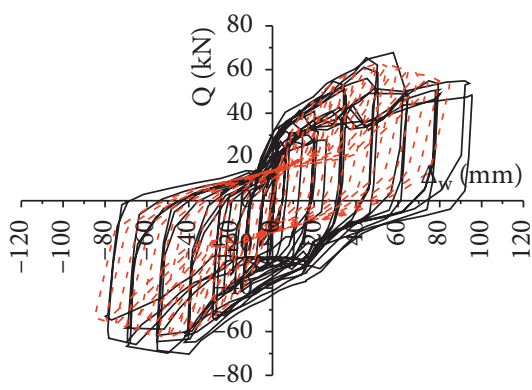

_ Test result [23]

- - - Simulated result

(e)

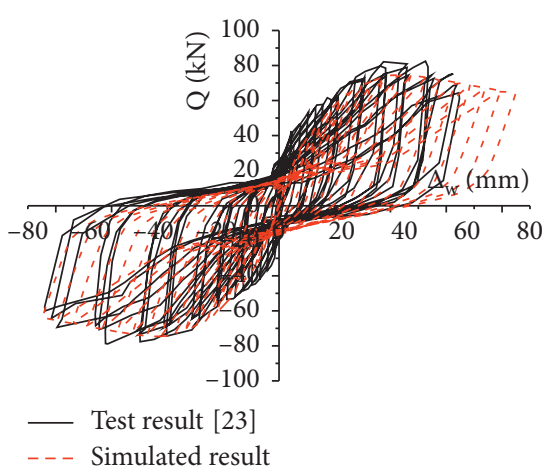

(h)

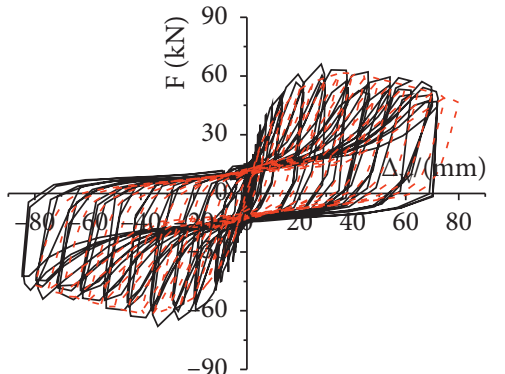

_ Test result [23]

- - - Simulated result

(c)

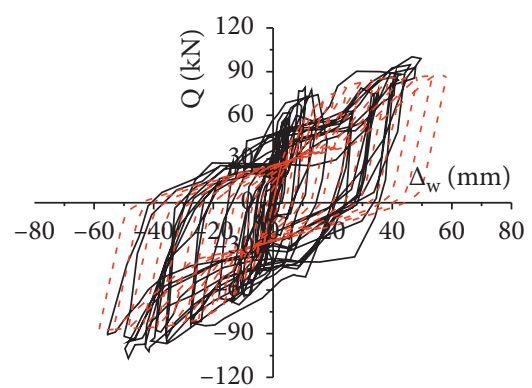

- Test result [23]

- - - Simulated result

(f)

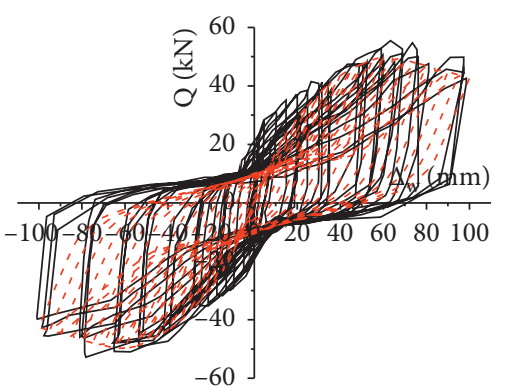

_ Test result [23]

- - - Simulated result

(i)

FIGURE 5: Comparisons of load-displacement curves. (a) Specimen RW1. (b) Specimen RW2. (c) Specimen RW3. (d) $1^{\text {st }}$ floor of specimen MRW1. (e) $2^{\text {nd }}$ floor of specimen MRW1. (f) $1^{\text {st }}$ floor of specimen MRW2. (g) $2^{\text {nd }}$ floor of specimen MRW2. (h) $1^{\text {st }}$ floor of specimen MRW3. (i) $2^{\text {nd }}$ floor of specimen MRW3.

TABle 4: Comparisons between the simulated and test results [18].

\begin{tabular}{|c|c|c|c|c|c|c|c|c|c|c|}
\hline Specimen number & Projects & $F_{\mathrm{e}}(\mathrm{kN})$ & $F_{\mathrm{y}}(\mathrm{kN})$ & $F_{\mathrm{p}}(\mathrm{kN})$ & $\Delta_{\mathrm{e}}(\mathrm{mm})$ & $\Delta_{\mathrm{y}}(\mathrm{mm})$ & $\Delta_{\mathrm{p}}(\mathrm{mm})$ & $\mu$ & $k_{300}(\mathrm{kN})(\mathrm{m})$ & $\kappa_{\max }(\%)$ \\
\hline \multirow{3}{*}{ RW1 } & Test & 40.6 & 78.1 & 101.5 & 4.26 & 12.15 & 28.15 & 2.99 & 1981 & \multirow{3}{*}{13.8} \\
\hline & FEM & 40.2 & 81.6 & 100.5 & 4.45 & 13.83 & 26.0 & 2.63 & 1892 & \\
\hline & $\kappa$ & $1.0 \%$ & $4.5 \%$ & $1.0 \%$ & $4.5 \%$ & $13.8 \%$ & $7.6 \%$ & $12.0 \%$ & $4.5 \%$ & \\
\hline \multirow{3}{*}{ RW2 } & Test & 50.6 & 83.7 & 126.5 & 3.62 & 8.02 & 30.73 & 6.36 & 1925 & \multirow{3}{*}{13.3} \\
\hline & FEM & 46.8 & 76.8 & 117.0 & 4.09 & 9.09 & 30.0 & 5.73 & 2068 & \\
\hline & $\kappa$ & $7.5 \%$ & $8.2 \%$ & $7.5 \%$ & $13.0 \%$ & $13.3 \%$ & $2.4 \%$ & $1.0 \%$ & $7.4 \%$ & \\
\hline \multirow{3}{*}{ RW3 } & Test & 38.2 & 80.3 & 95.4 & 4.93 & 17.76 & 40.52 & 3.17 & 1547 & \multirow{3}{*}{14.2} \\
\hline & FEM & 34.2 & 71.8 & 85.5 & 5.43 & 18.99 & 40.0 & 3.37 & 1327 & \\
\hline & $\kappa$ & $10.5 \%$ & $10.6 \%$ & $10.4 \%$ & $10.1 \%$ & $6.9 \%$ & $1.2 \%$ & $6.3 \%$ & $14.2 \%$ & \\
\hline
\end{tabular}

$F_{\mathrm{e}}, F_{\mathrm{y}}, F_{\mathrm{p}}$ are the elastic strength, yield strength, peak strength, and $\Delta_{\mathrm{e}}, \Delta_{\mathrm{y}}$, and $\Delta_{\mathrm{p}}$ are their relative displacements, respectively, where $F_{\mathrm{e}}=0.4 F_{\mathrm{p}}$ is the conventional elastic strength limit; $\Delta_{\mathrm{u}}$ is the relative displacement that corresponds to $0.85 F_{\mathrm{p}}$ beyond the peak load, and $\mu=\Delta_{\mathrm{u}} / \Delta_{\mathrm{y}}$ is the ductility coefficient; $k_{300}$ is the unit shear stiffness when the lateral displacement of a wall on top reaches $\mathrm{H} / 300 ; \kappa$ and $\kappa_{\max }$ are the relative error and its maximum value between the simulated and test results, respectively. 
TABLE 5: Details of sixteen numerical models.

\begin{tabular}{|c|c|c|c|c|c|c|c|}
\hline \multirow{2}{*}{ Model number } & \multirow{2}{*}{ Opening size $(\mathrm{b} \times \mathrm{h} / \mathrm{d}) / \mathrm{m}$} & \multirow{2}{*}{$r(\%)$} & \multicolumn{3}{|c|}{$F_{\mathrm{pc}}(\mathrm{kN})$} & \multirow{2}{*}{$\mathrm{b} / \mathrm{d}$} & \multirow{2}{*}{ Schemat } \\
\hline & & & FEM & SC & $\lambda(\%)$ & & \\
\hline IW1 & $0.9 \times 2.4 / 0.6$ & 20.0 & 97.3 & $*$ & 4.1 & 1.5 & \\
\hline IW2 & $0.9 \times 2.7 / 0.3$ & 22.5 & 93.0 & 85.5 & 8.8 & 3.0 & \\
\hline IW3 & $1.2 \times 2.4 / 0.6$ & 26.7 & 91.5 & 95.9 & 4.6 & 2.0 & $d$ \\
\hline IW4 & $1.5 \times 2.4 / 0.6$ & 33.3 & 82.9 & 86.2 & 3.8 & 2.5 & \\
\hline IW5 & $1.8 \times 2.4 / 0.6$ & 40.0 & 72.7 & 76.7 & 5.2 & 3.0 & $h$ \\
\hline IW6 & $1.2 \times 2.7 / 0.3$ & 30.0 & 87.3 & 90.1 & 3.1 & 4.0 & \\
\hline IW7 & $1.5 \times 2.7 / 0.3$ & 37.5 & 73.8 & 81.1 & 9.0 & 5.0 & \\
\hline IW8 & $1.8 \times 2.7 / 0.3$ & 45.0 & 66.1 & $55.6(50.8)$ & 18.9 & 6.0 & \\
\hline OW1 & $0.9 \times 1.5 / 0.6$ & 12.5 & 122.5 & $\#$ & 3.2 & 1.5 & \\
\hline OW2 & $1.2 \times 1.5 / 0.6$ & 16.7 & 112.8 & 119.4 & 5.5 & 2.0 & \\
\hline OW3 & $1.5 \times 1.5 / 0.6$ & 20.8 & 103.0 & 107.2 & 3.9 & 2.5 & $d$ \\
\hline OW4 & $1.8 \times 1.5 / 0.6$ & 25.0 & 93.7 & 95.4 & 1.8 & 3.0 & $b$ \\
\hline OW5 & $0.9 \times 1.8 / 0.3$ & 15.0 & 110.2 & 103.9 & 6.1 & 3.0 & $h$ \\
\hline OW6 & $1.2 \times 1.8 / 0.3$ & 20.0 & 98.8 & 92.8 & 6.5 & 4.0 & \\
\hline OW7 & $1.5 \times 1.8 / 0.3$ & 25.0 & 84.9 & 81.9 & 3.7 & 5.0 & \\
\hline OW8 & $1.8 \times 1.8 / 0.3$ & 30.0 & 75.5 & $69.2(63.2)$ & 9.1 & 6.0 & \\
\hline
\end{tabular}

$r=(\mathrm{b} \times \mathrm{h}) /(\mathrm{B} \times \mathrm{H})$ is the area ratio of the opening to that of the wall; $F_{\mathrm{pc}}$ represents the calculated shear capacities, including the simulated results $(\mathrm{FEM})$ and simplified calculated (SC) results calculated by the simplified method [18], and $\lambda$ is the absolute value of the relative error between FEM and SC; "** and "\#”, indicate the shear capacities of specimens RW1 and RW2 without an opening, respectively; and the values in the brackets are the relative shear strength corresponding to the net sheathed wall length except for the wall segment over the opening.

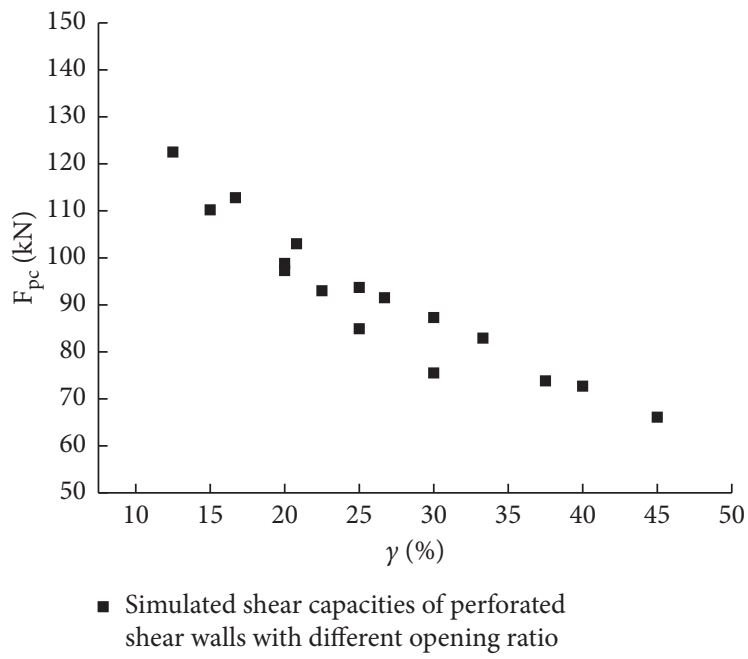

FIGURE 6: Shear capacity of the walls with different opening ratios.

agreements can be observed between the simulated and test curves, the relative errors of the characteristic parameters of skeleton curves between the simulated and test results, including the elastic shear strength $F_{\mathrm{e}}$, yield shear force $F_{\mathrm{y}}$, and peak shear strength $F_{\mathrm{p}}$, are within $14.5 \%$. The characteristics, such as nonlinearity, pinching, strength degradation, and stiffness degradation of the wall, are almost identical to the test results.

It should be noted that the simulated pinching loads of specimen MRW1 were significantly lower than those of the test results (see Figures 5(d) and 5(e)). This is because, during the test, all the studs in the lower wall segment of specimen MRW1 were compressed and buckled as the studs' section area was small. The positions of the lateral restraints on the top of each wall segment against the outplane deformation changed as the vertical deformation of the specimen increased, and a large friction between the lateral restraints and loading beam along with the joist thereby occurred, thus resulting in an increase in the horizontal force on the wall during the unloading-reverse loading.

It can also be observed from Table 6 that the simulated results, including the elastic shear strength $F_{\mathrm{e}}$, yield shear force $F_{\mathrm{y}}$, and peak shear strength $F_{\mathrm{p}}$, are all lower than the test results, which indicates that the improved fastener-based modelling method can be used to effectively predict the lateral performance of double-storey RCFS shear walls subjected to an inverted triangle load. 


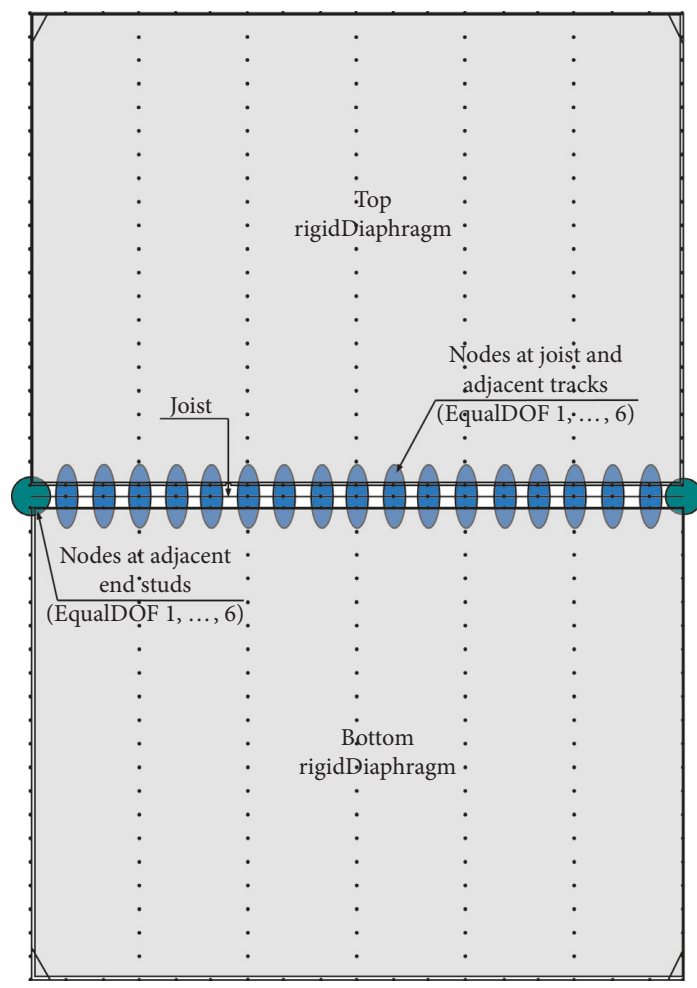

(a)

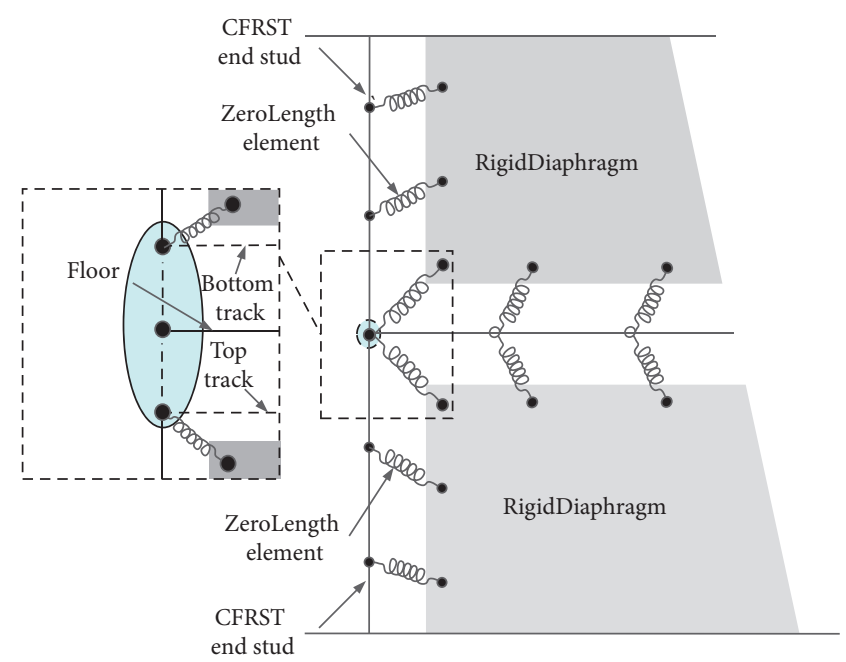

(b)

Figure 7: Numerical model of specimen MRW1. (a) Numerical model of mid-rise RCFS shear walls. (b) Detailed constraints of adjacent shear walls.

TABLE 6: Comparisons between the simulated and test results [23].

\begin{tabular}{|c|c|c|c|c|c|c|c|c|c|}
\hline \multirow{2}{*}{ Specimen number } & \multirow{2}{*}{ Projects } & \multirow{2}{*}{$F_{\mathrm{e}}(\mathrm{kN})$} & \multirow{2}{*}{$F_{\mathrm{y}}(\mathrm{kN})$} & \multirow{2}{*}{$F_{\mathrm{p}}(\mathrm{kN})$} & \multirow{2}{*}{$\Delta_{\mathrm{e}}(\mathrm{mm})$} & \multirow{2}{*}{$\Delta_{\mathrm{y}}(\mathrm{mm})$} & \multicolumn{2}{|c|}{$\Delta_{\mathrm{wm}}(\mathrm{mm})$} & \multirow{2}{*}{$\kappa_{\max }(\%)$} \\
\hline & & & & & & & $1^{\text {st }}$ floor & $2^{\text {nd }}$ floor & \\
\hline \multirow{3}{*}{ MRW1 } & Test & 37.9 & 79.8 & 94.7 & 3.4 & 15.1 & 34.8 & 46.1 & \multirow{3}{*}{8.9} \\
\hline & FEM & 37.6 & 73.5 & 94.0 & 3.5 & 14.7 & 37.9 & 50.0 & \\
\hline & $\kappa$ & $0.8 \%$ & $7.9 \%$ & $0.7 \%$ & $2.9 \%$ & $2.6 \%$ & $8.9 \%$ & $8.4 \%$ & \\
\hline \multirow{3}{*}{ MRW2 } & Test & 41.9 & 72.4 & 104.8 & 2.2 & 13.3 & 45.2 & 63.4 & \multirow{3}{*}{14.5} \\
\hline & FEM & 35.8 & 68.1 & 89.6 & 2.0 & 15.0 & 49.6 & 67.2 & \\
\hline & $\kappa$ & $14.6 \%$ & $5.9 \%$ & $14.5 \%$ & $9.1 \%$ & $11.3 \%$ & $9.7 \%$ & $6.0 \%$ & \\
\hline \multirow{3}{*}{ MRW3 } & Test & 32.0 & 55.5 & 79.9 & 2.1 & 13.1 & 47.8 & 66.9 & \multirow{3}{*}{8.1} \\
\hline & FEM & 29.4 & 53.2 & 73.4 & 2.0 & 14.8 & 46.4 & 67.5 & \\
\hline & $\kappa$ & $8.1 \%$ & $3.2 \%$ & $8.1 \%$ & $4.8 \%$ & $1.7 \%$ & $2.9 \%$ & $0.9 \%$ & \\
\hline
\end{tabular}

$\Delta_{\mathrm{wm}}$ is the horizontal displacement of each wall segment on the top with respect to the ground when the shear capacity is reached; the meaning of $F_{\mathrm{e}}, F_{\mathrm{y}}, F_{\mathrm{p}}, \Delta_{\mathrm{e}}$, $\Delta_{\mathrm{y}}, \kappa$, and $\kappa_{\max }$ are identical to those in Table 4.

\section{Summary and Conclusions}

In this study, a fastener-based computational model was improved and extended to predict the shear performance of RCFS shear walls. The conclusions of this study are summarised as follows:

(1) The simulated load-displacement hysteretic curves agree well with previously obtained test results and can fully reflect characteristics such as the nonlinearity, pinching, strength degradation, and stiffness degradation of the walls subjected to a horizontal load, thus confirming the validity of the improved fastener-based modelling method for
RCFS shear walls. Moreover, the relative errors between the simulated and test results of both the skeleton curves' characteristic parameters and unit shear stiffness $k_{300}$ when the lateral displacement of the wall on the top reaches $\mathrm{H} / 300$ are within $14.2 \%$, thus proving the reliability of parameter determination for sheathing-to-stud connections with double-layer wallboards.

(2) The application of the equivalent method of simplifying the wall segment over an opening as a linear elastic beam to perforated RCFS shear walls is closely related to the opening size. In the case of a perforated RCFS shear wall of a conventional size, the equivalent 
method is applicable in the case of $1.5<b / d$ (i.e., the ratio of the opening width to the depth of the wall segment over an opening) $\leq 5.0$.

(3) The simulated results for double-storey RCFS shear walls, including the shear-force-displacement hysteresis curves and characteristic parameters of skeleton curves, are in good agreement with the test results, and their relative errors are within 14.5\%. Furthermore, the simulated results, including the elastic shear strength $F_{\mathrm{e}}$, yield shear force $F_{\mathrm{y}}$, and peak shear strength $F_{\mathrm{p}}$, are all lower than those of the test results, which indicates that the improved fastener-based modelling method can effectively predict the lateral performance of mid-rise RCFS shear walls.

\section{Data Availability}

The data used to support the findings of this study are available from the corresponding author upon request.

\section{Conflicts of Interest}

The authors declare that they have no conflicts of interest.

\section{Acknowledgments}

The work described in this article was supported by the National Natural Science Foundations of China (51708258 and 51708257) and the Science and Technology Project for Construction System in Jiangsu Province (2018ZD093).

\section{References}

[1] O. Iuorio, L. Fiorino, and R. Landolfo, "Testing CFS structures: the new school BFS in Naples," Thin-Walled Structures, vol. 84, pp. 275-288, 2014.

[2] W. Khaliq and A. Moghis, "Shear capacity of cold-formed light-gauge steel framed shear-wall panels with fiber cement board sheathing," International Journal of Steel Structures, vol. 17, no. 4, pp. 1404-1414, 2017.

[3] R. Landolfo, L. Fiorino, and G. D. Corte, "Seismic behavior of sheathed cold-formed structures: physical tests," Journal of Structural Engineering, vol. 132, no. 4, pp. 570-581, 2006.

[4] J. Lange and B. Naujoks, "Behaviour of cold-formed steel shear walls under horizontal and vertical loads," Thin-walled Structures, vol. 44, no. 12, pp. 1214-1222, 2006.

[5] V. Macillo, L. Fiorino, and R. Landolfo, "Seismic response of CFS shear walls sheathed with nailed gypsum panels: experimental tests," Thin-Walled Structures, vol. 120, pp. 161171, 2017.

[6] M. Nithyadharan and V. Kalyanaraman, "Behaviour of coldformed steel shear wall panels under monotonic and reversed cyclic loading," Thin-walled Structures, vol. 60, pp. 12-23, 2012.

[7] C.-L. Pan and M.-Y. Shan, "Monotonic shear tests of coldformed steel wall frames with sheathing," Thin-walled Structures, vol. 49, no. 2, pp. 363-370, 2011.

[8] H.-W. Tian, Y.-Q. Li, and C. Yu, "Testing of steel sheathed cold-formed steel trussed shear walls," Thin-walled Structures, vol. 94, pp. 280-292, 2015.

[9] S.-H. Lin, C.-L. Pan, and W.-T. Hsu, "Monotonic and cyclic loading tests for cold-formed steel wall frames sheathed with calcium silicate board," Thin-walled Structures, vol. 74, pp. 49-58, 2014.

[10] M. Zeynalian and H. R. Ronagh, "Seismic performance of cold formed steel walls sheathed by fibre-cement board panels," Journal of Constructional Steel Research, vol. 107, pp. 1-11, 2015.

[11] B. Eray and A. Cagatay, "Behavior of cold-formed steel wall panels under monotonic horizontal loading," Journal of Constructional Steel Research, vol. 79, pp. 1-8, 2012.

[12] S. Iman, D. Jamin, and A. R. Colin, "Dynamic testing of single- and double-story steel-sheathed cold-formed steelframed shear walls," Journal of Structural Engineering, ASCE, vol. 139, no. 5, pp. 807-817, 2013.

[13] S. Mohebbi, R. Mirghaderi, F. Farahbod, and A. Bagheri Sabbagh, "Experimental work on single and double-sided steel sheathed cold-formed steel shear walls for seismic actions," Thin-walled Structures, vol. 91, pp. 50-62, 2015.

[14] Z. Xuhong, S. Yu, and Z. Tianhua, "Study on shear resistance of cold-formed steel stud walls in residential structures," Journal of Building Structures, vol. 27, no. 3, pp. 42-47, 2006, in Chinese.

[15] S. E. Niari, B. Rafezy, and K. Abedi, "Seismic behavior of steel sheathed cold-formed steel shear wall: experimental investigation and numerical modeling," Thin-walled Structures, vol. 96, pp. 337-347, 2015.

[16] K. D. Peterman, N. Nakata, and B. W. Schafer, "Hysteretic characterization of cold-formed steel stud-to-sheathing connections," Journal of Constructional Steel Research, vol. 101, pp. 254-264, 2014.

[17] S. G. Buonopane, G. Bian, T. H. Tun, and B. W. Schafer, "Computationally efficient fastener-based models of coldformed steel shear walls with wood sheathing," Journal of Constructional Steel Research, vol. 110, pp. 137-148, 2015.

[18] X. Wang and J. Ye, "Reversed cyclic performance of coldformed steel shear walls with reinforced end studs," Journal of Constructional Steel Research, vol. 113, pp. 28-42, 2015.

[19] S. Mingzhou, H. Zhiguang, S. Jian, Q. Yan, and S. Lin, "Experimental study of the shearing behavior of cold-formed steel wall panels under cyclic load," China Civil Engineering Journal, vol. 44, no. 8, pp. 42-51, 2011, in Chinese.

[20] A. J. Salenikovich, J. D. Dolan, and W. S. Easterling, "Racking performance of long steel-frame shear walls," in Proceedings of the 15th International Specialty Conference on Cold-Formed Steel Structures, pp. 471-480, St. Louis, MO, USA, October 2000.

[21] L. Yuanqi, L. Fei, S. Zuyan, and H. Huiwen, "Experimental investigation on seismic behavior of S350 light-gauge composite framing walls," China Civil Engineering Journal, vol. 45, no. 12 , pp. 83-90, 2012, in Chinese.

[22] X. Wang, J. Ye, and Q. Yu, "Improved equivalent bracing model for seismic analysis of mid-rise CFS structures," Journal of Constructional Steel Research, vol. 136, pp. 256-264, 2017.

[23] X. Wang and J. Ye, "Cyclic testing of two- and three-story CFS shear-walls with reinforced end studs," Journal of Construction Steel Research, vol. 121, pp. 13-28, 2016.

[24] J. Ye, X. Wang, H. Jia, and M. Zhao, "Cyclic-performance of cold-formed steel shear walls sheathed with double-layer wallboards on both sides," Thin-Walled Structures, vol. 92, pp. 146-159, 2015.

[25] X. Wang, J. Ye, and W. Wei, "Experimental investigation on the structural performance of a reinforced cold-formed steel beam-column joint," Canadian Journal of Civil Engineering, vol. 45, no. 12, pp. 1027-1039, 2018. 
[26] J. Ye, X. Wang, and M. Zhao, "Experimental study of shear behavior of screw connections in CFS sheathing," Journal of Construction Steel Research, vol. 121, pp. 1-12, 2016.

[27] J. Ye, R. Feng, W. Chen, and W. Liu, "Behavior of cold-formed steel wall stud with sheathing subjected to compression," Journal of Construction Steel Research, vol. 116, pp. 79-91, 2016.

[28] F. Mckenna, "OpenSees: the open system for earthquake Engineering simulation,” 2014, http://opensees.berkeley.edu. 


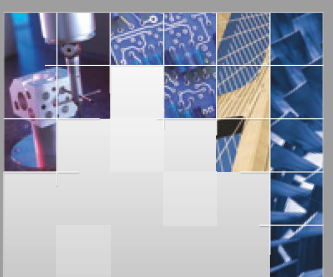

\section{Enfincering}
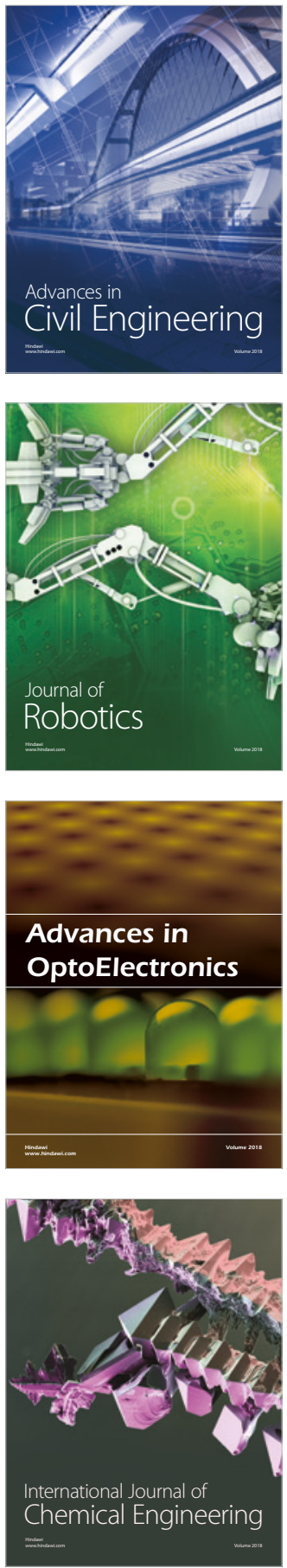

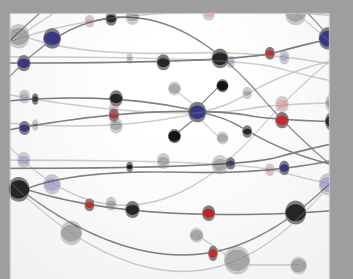

\section{Rotating \\ Machinery}

The Scientific World Journal

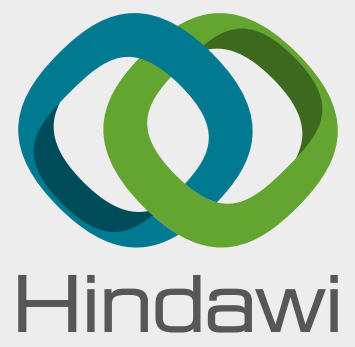

Submit your manuscripts at

www.hindawi.com
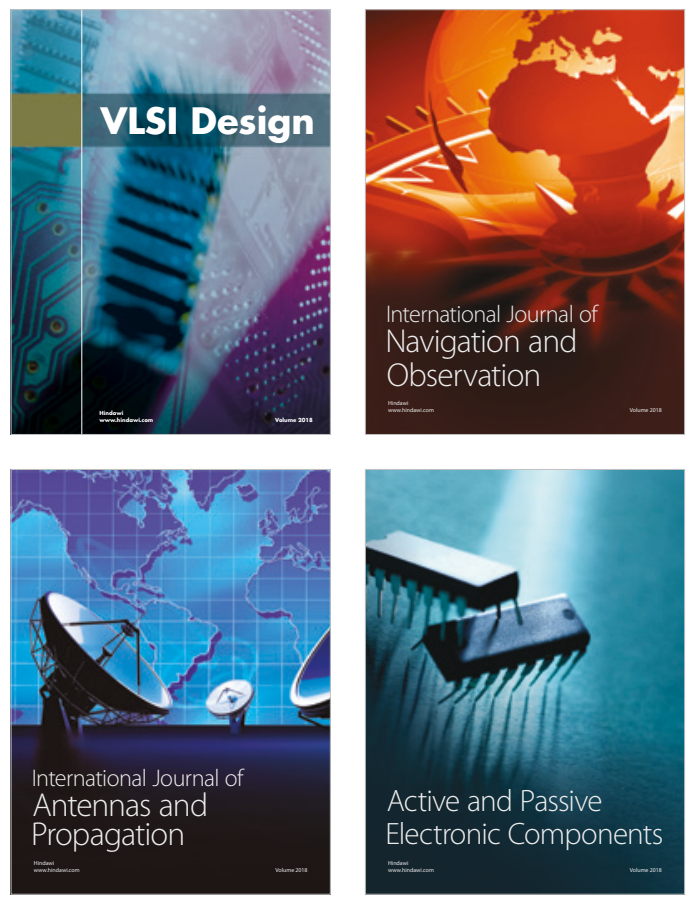
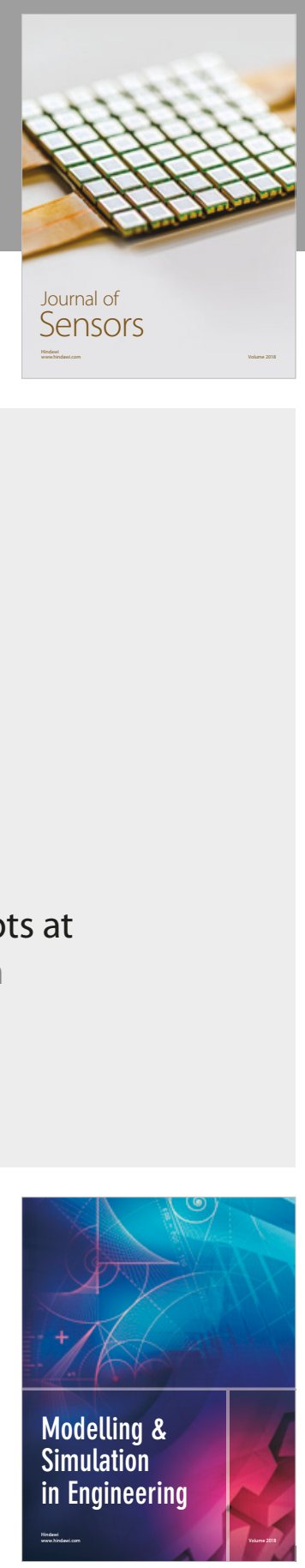

\section{Advances \\ Multimedia}
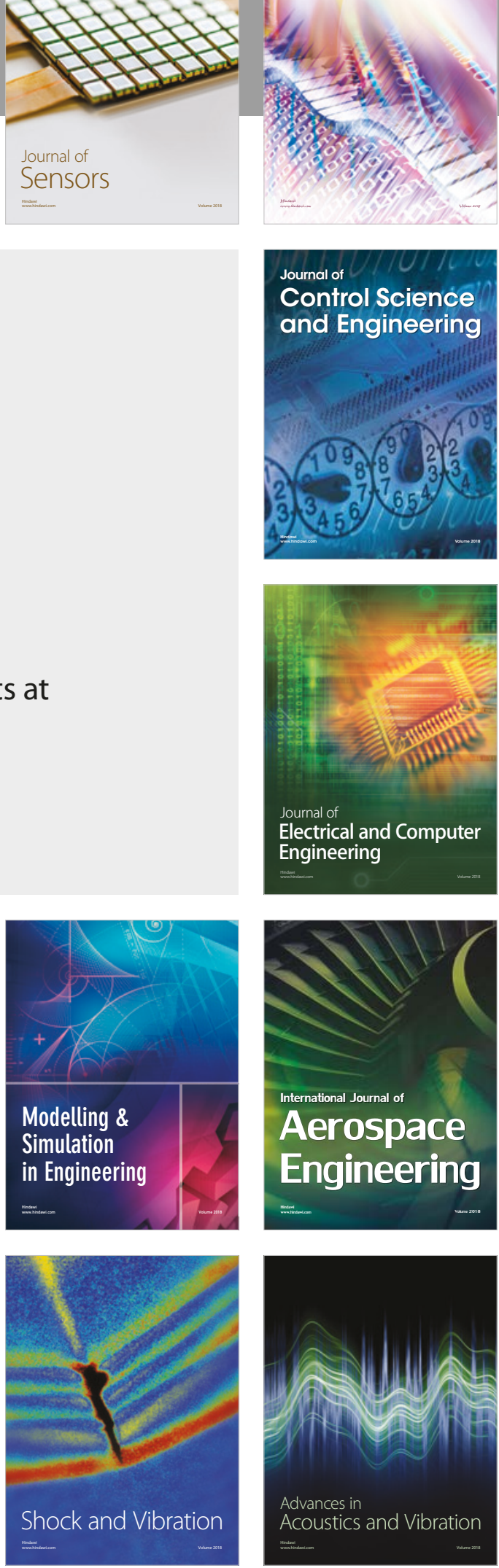